\title{
Processing, Characterization and Application of Some Borophosphate Glasses Containing Antibacterial and Antifungal Oxides in Bioactive Demands
}

\author{
M. A. Ouis ${ }^{1 *}$, A. A. Fayad ${ }^{1}$, A. A. Abd El Aty ${ }^{2,3}$, G. T. El-Bassyouni ${ }^{4}$ \\ ${ }^{1}$ Glass Research Dept., National Research Centre (NRC), Dokki, Giza, Egypt \\ ${ }^{2}$ Chemistry of Natural and Microbial Products Dept., National Research Centre \\ (NRC) Dokki, Giza, Egypt \\ ${ }^{3}$ Biology Dept., Faculty of Education, Hafr Al Batin University, KSA. \\ ${ }^{4}$ Refractories, Ceramics and Building Materials Department, National Research \\ Centre (NRC), Dokki, Giza, 12622, Egypt
}

\begin{abstract}
SERIES of borophosphate glasses doped individually with few antimicrobial oxides; $\mathrm{CeO}_{2}$, $\mathrm{ZnO}$ and $\mathrm{CuO}$ were prepared by melt quenching technique. The structure and bioactivity of the prepared samples were analyzed through FTIR spectral technique and corrosion behavior before and after immersion for 2 weeks in simulated body fluid (SBF) under static condition. The microstructure of the glass was examined using SEM to confirm the bioactivity of glass through the formation of calcium phosphate $(\mathrm{CaP})$ layer on the surface. FTIR spectra of the glass after immersion in SBF show characteristic peaks of calcium phosphate. Weight loss\% display a difference in solubility in the SBF solution in relation to the antibacterial oxide added. SEM results show clear nodular microcrystalline calcium phosphate. The prepared glasses revealed effect against some microbes and bacteria. It was established that the addition of the antimicrobial oxides had a positive effect on the glass bioactivity and may find a part in the biomedical applications.
\end{abstract}

Keywords: Borophosphate glasses, bioactivity, FTIR, SEM,Antibacterial-antifungal glass.

\section{Introduction}

Bioactive glasses (BG) were known and applied in medicinal field especially in orthopedics, otology and dentistry, a long time ago [1]. Firstly, bioactive materials were prepared to eliminate bone deficiencies, but later, they applied in tissue engineering and therapeutic uses [1]. Dental implants, bone substantial, soft tissue renewal are the traditional applications of BG. But the interesting issue in the coming period is how to increase the antibacterial properties of $\mathrm{BG}$ and how to be benefit in different therapeutic uses [1].

The importance of borophosphate glasses is coming from their high valuable collective structural chemistry and uses in sorption and separation, heterogeneous catalysis photonic technologies, ion exchange and others. Borates and phosphates reveal a complicated construction which increases the tendency to create polynuclear anionic units [2]. The building of anions in both boron-oxygen tetrahedron and phosphorusoxygen tetrahedron with several unifications, in borophosphate glasses, is of high importance because of their uses in plasma display panel (PDP) phosphorus, and scintillation materials. The chemical durability, thermal and mechanical stability of phosphate glasses is improved by the addition of $\mathrm{B}_{2} \mathrm{O}_{3}$ to a phosphate network [3]

Living body and alkaline earth borophosphates are able to contact through biological reaction [4]. Human bone inorganic phase consists basically of calcium and phosphate. So glasses of calcium phosphate main composition were studied in therapeutic demands because they produce biologically active calcium phosphate $(\mathrm{CaP})$ layer which upsurges the attachment between bone and soft tissues [5-7].

Bioactive glass doped with different antibacterial oxides $\left(\mathrm{CeO}_{2}, \mathrm{ZnO}, \mathrm{CuO}\right)$ which have biological features have been explored outside human body to form alloplastic materials effectively [7].

Cerium has a stable character against bacteria, consequently bioactive glasses containing cerium is valued in many applications like implantation 
into periodontal pockets, infected frontal sinuses and hypersensitive teeth $[8,9]$.

Bone construction and cell progression are basically independent on zinc element $[10,11]$. Many enzymes based on zinc as a cofactor, preparation of protein and DNA reproduction also depend on zinc $[11,12]$. A lack of zinc leads to the delay in skeleton progression and changes in ordering of bone tissue [13]. Chemical durability of many glasses containing $\mathrm{Zn}$, increased by slowing down their dissolution in aqueous solutions [in vitro body fluids] and increasing the mechanical properties [14]. Copper $(\mathrm{Cu})$ is a vital ion with valuable properties in the human body. Because its favorable role on endothelial cells, it performs a major part in angiogenesis and blood vessel maturation process [15].

The aim of the present work is to study the effect of addition of different oxides $\left(\mathrm{CeO}_{2}\right.$, $\mathrm{ZnO}, \mathrm{CuO}$ ) on the bioactivity and antimicrobial behavior of borophosphate glasses in order to develop effective bioactive materials.

\section{Materials and methods}

\section{Preparation of glass}

The glass system was prepared by mixing starting reagents [orthoboric acid for $\mathrm{B}_{2} \mathrm{O}_{3}$, ammonium dihydrogen phosphate for $\mathrm{P}_{2} \mathrm{O}_{5}$, calcium fluoride for $\mathrm{CaF}_{2}$, sodium carbonate for $\left.\mathrm{Na}_{2} \mathrm{O}\right]$ in the calculated quantities. Cerium, zinc, copper oxides for $\mathrm{CeO}_{2}, \mathrm{ZnO}$, and $\mathrm{CuO}$ as shown in Table 1. Weighted batches were homogeneously mixed via an agate mortar before melting for 2 hours in covered porcelain crucibles at $1200^{\circ} \mathrm{C}$. The melts were rotated at intervals to attain homogeneity. The prepared glasses were transferred to a muffle furnace regulated at $280^{\circ} \mathrm{C}$ for annealing. The melted ingot was crushed in an agate mortar and sieved to obtain particles of size (0.3-0.6 mm)

\section{Structural and bioactivity characterization}

\section{FTIR measurements}

FT Infrared absorption spectra of the prepared glasses were measured at room temperature in the wavenumber range of 4000-400 $\mathrm{cm}^{-1}$ using FTIR spectrophotometer (Type Matson 5000, USA). Fine powder of the samples was mixed with $\mathrm{KBr}$ in the ratio 1:100 for qualitative analysis and the mixture was subjected to a load of 5 tons $/ \mathrm{cm}^{2}$ in an evocable die to produce clear homogeneous discs. The measurements were taken pre and post immersion of the prepared glasses in SBF solution.

\section{Weight loss $\%$}

$1 \mathrm{~g}$ of glass grains $(0.3-0.6 \mathrm{~mm})$ was soaked in $100 \mathrm{ml}$ of SBF solution for 2 weeks at $37^{\circ} \mathrm{C}$. Degradation degree (weight loss, \%) of the prepared glass was valued as:

$\mathrm{Wt}$ loss $\%=\left(\mathrm{W}_{\mathrm{i}}-\mathrm{W}_{\mathrm{t}}\right) / \mathrm{W}_{\mathrm{i}} \times 100$

Where $\mathrm{W}_{\mathrm{i}}$ is the weight of glass powder before immersion, and $\mathrm{W}_{t}$ is the weight of glass powder after immersion for a time (t) [16].

TABLE 1. Composition of prepared glasses.

\begin{tabular}{|c|c|c|c|c|c|c|c|}
\hline $\mathrm{Wt} \%$ & $\mathrm{~B}_{2} \mathrm{O}_{3}$ & $\mathrm{P}_{2} \mathrm{O}_{5}$ & $\mathrm{CaF}_{2}$ & $\mathrm{Na}_{2} \mathrm{O}$ & $\mathrm{CeO}_{2}$ & $\mathrm{ZnO}$ & $\mathrm{CuO}$ \\
\hline Blank & 30 & 40 & 5 & 25 & -- & -- & -- \\
$\mathrm{G} 1$ & 30 & 40 & 5 & 25 & 3 & --- & -- \\
$\mathrm{G} 2$ & 30 & 40 & 5 & 25 & -- & 3 & - \\
$\mathrm{G} 3$ & 30 & 40 & 5 & 25 & -- & -- & 3 \\
\hline
\end{tabular}

SEM

For SEM imaging, samples were sputtered with gold. The surface texture and morphology of the prepared samples were characterized using SEM [SEM Model Quanta FEG 250, Holland].

\section{Antibacterial properties}

Biology experiments

\section{In-vitro antimicrobial activities}

The antibacterial and antifungal activities of prepared glasses were determined by means of the agar diffusion method according to

Egypt.J.Chem. 61, No.1 (2018) 
Sherief et al., 2016 \&El-Batal et al., 2017[17, 18]. All samples were screened in-vitro against different pathogenic strains of Gram positive (Bacillus subtilis ATCC6633 and Staphylococcus aureus ATCC29213), Gram negative bacteria (Escherichia coli ATCC25922 and Pseudomonas aeruginosa ATCC27953), yeast (Candida albicans ATCC10321) and fungi (Aspergillus niger NRC53 and Fusariumsolani NRC15). Bacteria and yeast strains are American Type Culture Collection, and fungal isolates were obtained from the culture collection of the Department of Chemistry of Natural and Microbial Products, National Research Center (NRC), Giza, Egypt. In antimicrobial test, the spore suspension of pathological strains was prepared and adjusted to be approximately $\left(1 \times 10^{6}\right.$ spores $^{-\mathrm{ml}}$ of fungi and $1 \times 10^{8}$ spores $^{\mathrm{ml}}$ of bacteria). $1 \mathrm{ml}$ of spore suspensions was inoculated into each plate containing $50 \mathrm{ml}$ of sterile potato dextrose agar (PDA) and nutrient agar medium (NA), respectively. After the media had cooled and solidified, About $100 \mathrm{mg}$ of the powder samples were applied on the inoculated agar plates and incubated for $24 \mathrm{~h}$ at $30^{\circ} \mathrm{C}$ for bacteria and yeast, $72 \mathrm{~h}$ at $28^{\circ} \mathrm{C}$ for fungi. The observation of the Halo zones was carried out to assess the antimicrobial activity. The antimicrobial effect was evaluated by measuring the inhibition zone diameter (IZD) around samples in (mm).

\section{Results and Discussion}

Hard work has been made to combine elements into the bioactive glass matrix [19]. So as to amend the glass functionality, bioactive and biological response of bioactive glass, replacement with different trace elements has been considered [20-22]. The glass network connectivity of unsubstituted glass reduced upon the addition of $\mathrm{CeO}_{2}$, which mainly acts as a network modifier. Particularly, the oxygen buffering capacity of ceria is well recognized [23].Cerium oxide as redox-active rare earth ions grown wide interest in the biomedical field owing to its potential therapeutic applications in metabolic bone, cancer and infectious diseases. Whereas, $\mathrm{ZnO}$ doing as intermediate ions is a crucial trace element that stimulates bone formation [24, 25]. Copper oxide $(\mathrm{CuO})$ is an indispensable ion in the human body aimed at its significant role in the course of angiogenesis and the maturation of blood vessels. $\mathrm{CuO}$ has a positive effect on the antibacterial mechanism. As a result, in common bone implant infections $\mathrm{CuO}$ seems to be a talented option for aerobic bacterial inhibitor systems [26].

Infrared absorption spectra of the prepared glasses before immersion in $S B F$

Figure 1 shows the FTIR absorption spectra of the as-prepared glass powders. The following features are illustrated:An intense IR broad band is observed showing three peaks at 3550, 3480, 3418 $\mathrm{cm}^{-1}$, two small peaks at 2925 and $2857 \mathrm{~cm}^{-1}$, a kink at $2364 \mathrm{~cm}^{1}$, two peaks at 1721 and $1632 \mathrm{~cm}^{-1}$, a broad band at $1400 \mathrm{~cm}^{-1}$, a broad band at 1176 $\mathrm{cm}^{-1}$, a band at $618 \mathrm{~cm}^{-1}$. The absorption bands from $1400-1150 \mathrm{~cm}^{-1}$ are typical of the vibrations of non-bridging $\mathrm{PO}_{2}$ groups. While the bands in region of $1150-900 \mathrm{~cm}^{-1}$, vibrations of terminal $\mathrm{P}-\mathrm{O}$ and $\mathrm{PO}_{3}$ groups can be found. The range of $900-700 \mathrm{~cm}^{-1}$ illustrate the vibrations of bridging P-O-P groups [16]. In contrast, borate groups show three active IR spectral regions which are: Bending vibration of borate segments arises in the range of $800-600 \mathrm{~cm}^{-1}$, B-O stretching vibration of triangular $\mathrm{BO}_{3}$ units such as meta-borate chains, pyro-borate and orthoborate groups in the range of 1500 and $1200 \mathrm{~cm}^{-1}$ and B-O stretching vibration of the tetrahedral $\mathrm{BO}_{4}$ units such as tetra-borate and di-borate groups are in the range of 1200-850 $\mathrm{cm}^{-1}[16]$. Spectra reveal the absence of boroxol rings which may exist at $806 \mathrm{~cm}^{-1}$.

The bands at 1400 and $1176 \mathrm{~cm}^{-1}$ are caused by $\mathrm{PO}_{2}, \mathrm{BO}_{3}$, and $\mathrm{BO}_{4}$ groups. Band at $1161 \mathrm{~cm}^{-1}$ is attributable to vibrations of $\mathrm{P}-\mathrm{O}$ and $\mathrm{BO}_{4}$ groups. The vibration band at $618 \mathrm{~cm}^{-1}$ is related to borate segments. Molecular $\mathrm{H}_{2} \mathrm{O}$ or $\mathrm{OH}$ group is situated at $1632 \mathrm{~cm}^{-1}$. The bands at $3418,2925,2857 \mathrm{~cm}^{-1}$ are correlated to the different modes of water [OH, P-OH and B-OH] [27].

FTIR spectra of the prepared glasses after immersion in SBF solution

Figure 2 demonstrated the FTIR spectra of the surface of the prepared glass powder after soaking in SBF for 2 weeks. Accordingly, FTIR spectra illustrated increase in the sharpness of absorbance bands at $1617,1721 \mathrm{~cm}^{-1}$ and a decrease in the intensity of the two bands 2925 and $2850 \mathrm{~cm}^{-1}$. The appearance of two bands at about 623 and 481 $\mathrm{cm}^{-1}$ were barely detected. Such bands correspond to the vibration mode of crystalline $\mathrm{P}-\mathrm{O}$, in the $\left(\mathrm{PO}_{4}^{3-}\right)$ orthophosphate groups are well anticipated to the formation of amorphous calcium phosphate (ACP) at the initial stage of conversion in SBF. ACP confirms the bioactivity of the studied glass. Apparently ACP is a precursor to the formation of the crystalline HA phase. 


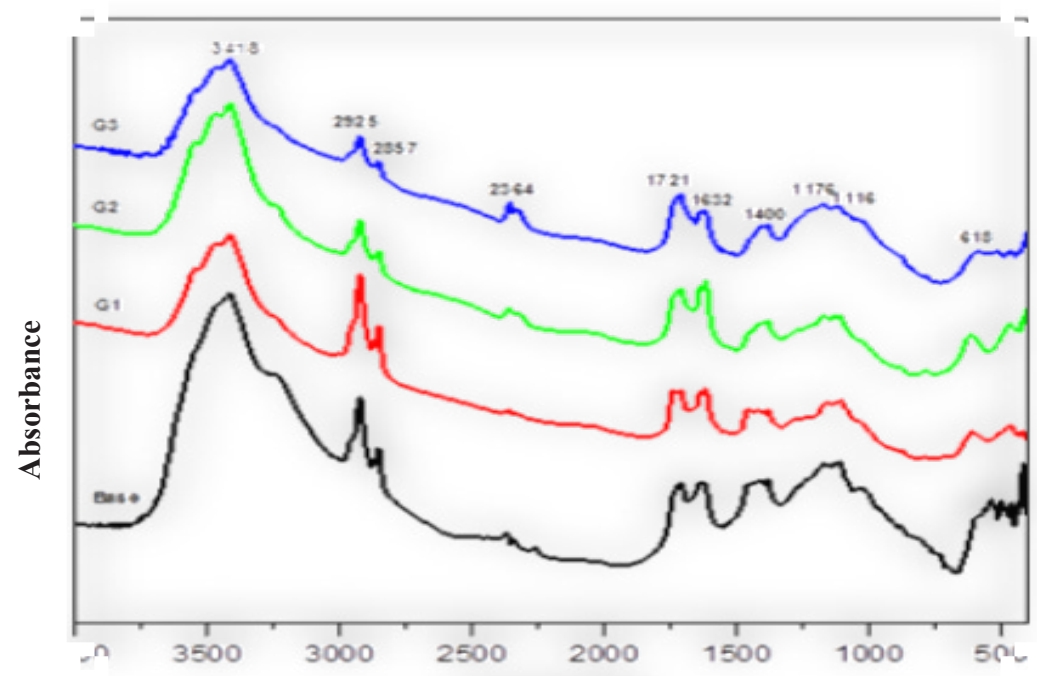

Wavenumber (cm-1)

Fig.1. FTIR spectra of prepared glasses before immersion in SBF solution.



Fig.2. FTIR spectra of prepared glasses after immersion in SBF solution.

Egypt.J.Chem. 61, No.1 (2018) 


\section{Weight loss $\%$}

The dissolution behavior of bioactive glass in SBF has a considerable effect on the antibacterial properties of the glass [1]. Particles of size of selected in this experiment because; smaller particle size can have a significant effect on the antibacterial efficiency of the material. As the reduction in size increases the active surface area and subsequently enhances the release of ions [28-30]. The dissolution behavior directly affects the microbial infections that may occur on the future implanting of the materials in the living body [31].

The corrosion behavior of borate glasses can be interpreted as follows [32]. With some variations in the degree of solubility to all constituents, borate glasses having alkali and/or alkaline earth oxides are properly soluble in aqueous solutions. The tetrahedral $\mathrm{BO}_{4}$ borate glasses will be less soluble in aqueous solutions than glasses with high content of triangular borate $\left(\mathrm{BO}_{3}\right)$ groups. The addition of alkaline earth oxide (e.g. $\mathrm{CaO}$ ) to sodium borate glass probably decreases the solubility of glass. This might be attributed to the introduction of doubly charged cations and their interfering in the solubility process and diffusion through the percolating channels in the glass network forming $\mathrm{CaOH}[33]$. The weight loss $\%$ data could be explained as follows: (a) Several factors control the dissolution process of borate glasses, such as: glass constituents, the duration and temperature of corrosion and the nature of leaching solution (i.e., constituent ionic species). (b) In the dissolution of soda lime borate glasses, Day et al.[33] expected a conversion process in which both sodium and borate ions dissolve in the leaching solution. However, the calcium ions from the glass will react with phosphate ions from the solution to form a calcium phosphate precipitate [34]. The formation of such precipitate was supposed to start at the glass surface before moving inward [35-37].(c) By changing the antibacterial elements, there will be a difference in the weight $\operatorname{loss} \%$. This could be clarified by considering different parameters, including the differences in the ionic radii of the respective cations and/or the interfering of numerous mixed ions throughout the dissolution method. (d)Upon addition of $\mathrm{CeO}_{2}$, the weight loss $\%$ will increase the interaction of $\mathrm{Ce}^{2+}$ ions with the phosphate ions. A highly soluble product will be formed which exceeds that of both calcium and sodium ions. Calcium ions have the affinity to form a mixture of calcium phosphate.According to our results; the addition of cerium oxide is more antimicrobial than zinc and copper oxides as shown in Fig. 3.

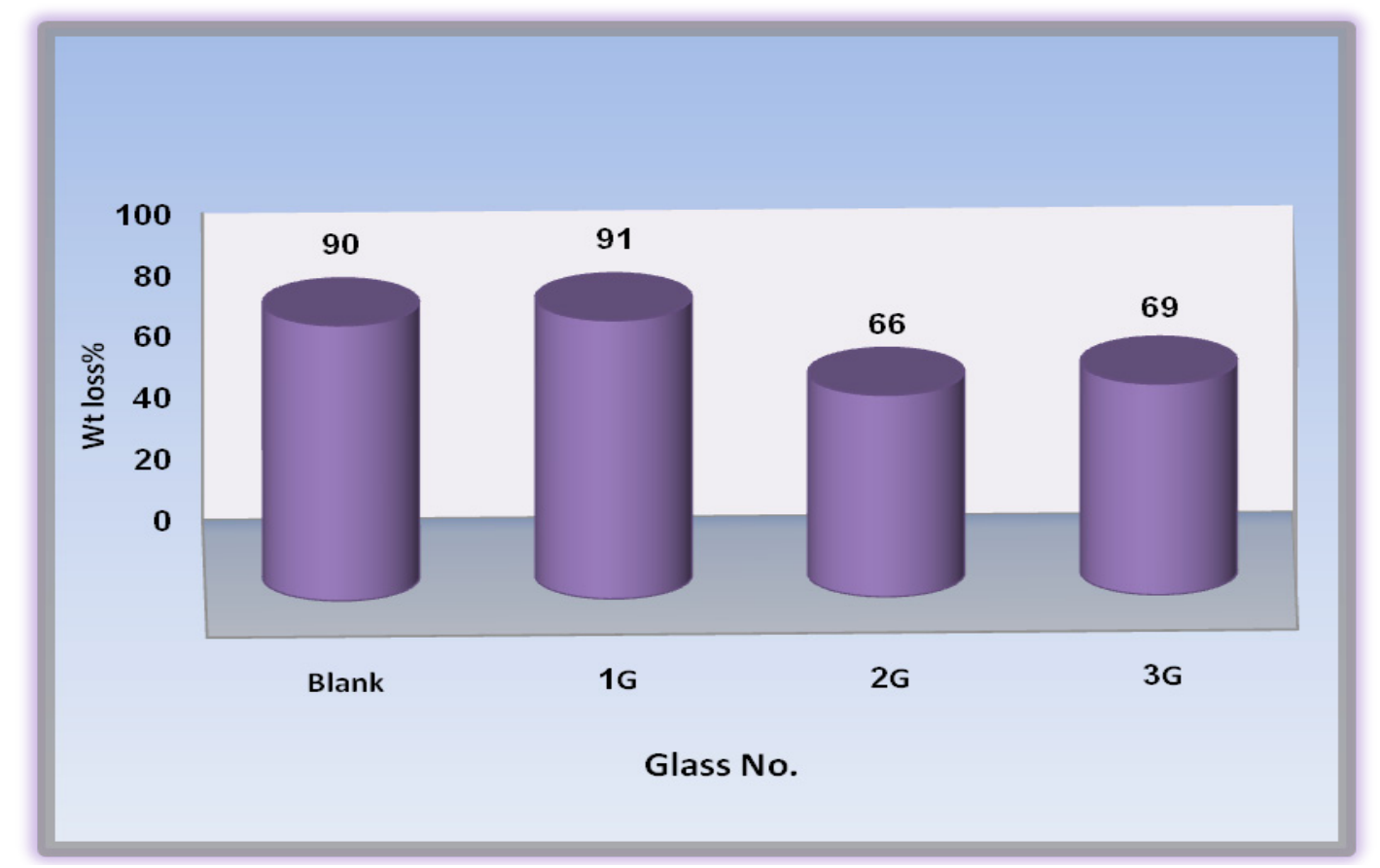

Fig.3. Wt loss\% data of prepared glasses after immersion in SBF solution. 


\section{SEM}

After samples immersion in SBF for 2 weeks, the SEM micrographs of the glass surface are presented in Fig. 4. Bioactive glasses convert to an amorphous calcium phosphate (ACP) or HAlike material [38,39], which is in charge for their resilient bonding with the nearby tissue [40]. SEM micrographs exhibited a second phase material seemingly an amorphous calcium phosphate based material has entirely covered the surface of the samples (Fig. 4). As a function of doping element concentration, almost minor significant difference was observed on the shape and morphology of the borophosphate. While, in the case of glasses with cerium content a spherical second phase material of regular aggregates was observed on the surface, presumably an amorphous calcium phosphate or HA, mainly formed by cerium and phosphate [41]. The degradation of the borate bioactive glass in SBF occurs by the dissolution of components, such as $\mathrm{Na}_{2} \mathrm{O}$ and $\mathrm{B}_{2} \mathrm{O}_{3}$ into the solution to form $\mathrm{Na}^{+},\left(\mathrm{BO}_{3}\right)^{2}-$, coupled with the reaction of $\mathrm{Ca} 2+$ ions from the glass with $\mathrm{PO}_{3} 4$ - from the solution to form the calcium phosphate layer on the glass [42]. Cerium content resulted in the formation of calcium rich HA layer over 14 days. This was attributed to the release of cerium ions which in turn competes with $\mathrm{Ca}$ ions to form phosphates [42].In our glass system, all SEM images show a spherical shape which has better activity against bacterial infections in comparison to the needlelike form.
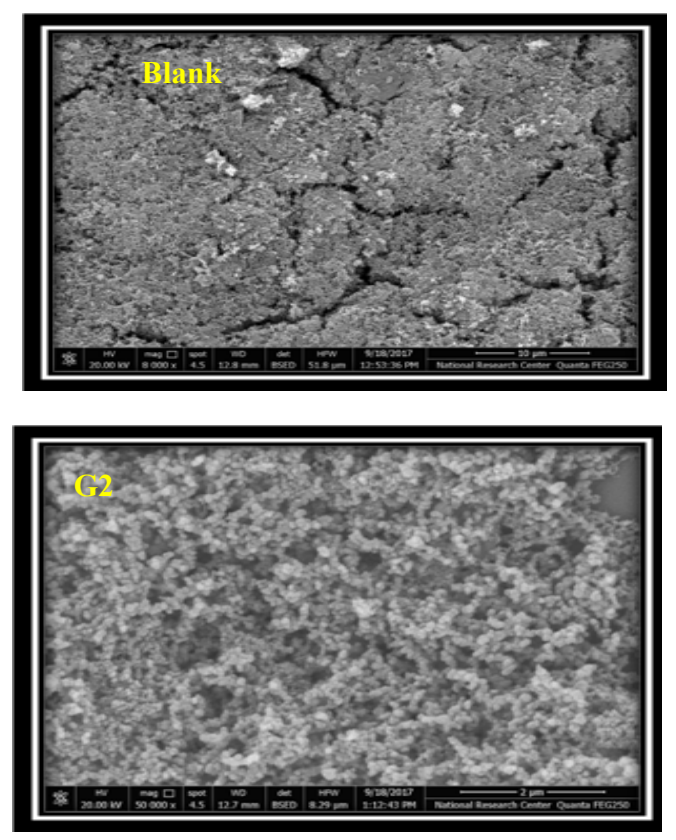

\section{Antimicrobial experiment}

The agar diffusion assay of the prepared glasses demonstrated different antimicrobial effects against tested micro-organisms depending on the sample composition. Table 2 \& Fig.5\&6 designate that, glass G1 exhibited an inhibitory effect against Gram positive bacteria B. subtilis and S. aureus with zones of the inhibition 17 and $16 \mathrm{~mm}$, respectively. While glass G2 showed good wide range of antimicrobial activities against most of the micro-organisms tested with zones of inhibition range from 13 to $18 \mathrm{~mm}$. Results also indicated that S. aureus, C. albicans and F. solani were found to be the most susceptible microorganisms to glass G3 with zones of inhibition of 14,16 and $25 \mathrm{~mm}$. This result evidences that the $\mathrm{G} 2$ \& $\mathrm{G} 3$ release $\mathrm{Zn}$ or $\mathrm{Cu}$ ions which react with proteins in the micro-organism causing the inactivation of proteins. The integration of $\mathrm{Cu}^{2+}$ in the borophosphate samples conveyed a development in the antibacterial effects [43]. The yield of antibacterial activity is well-defined conferring to numerous variables, including grain size, electron structure of the catalytic sample, speed of solubility, and nature of the microorganism considered for inactivation. For example, $\mathrm{Cu}^{2+}$ directed to a decrease in solubility but, due to the higher proportion of special surface to volume, the release of $\mathrm{Cu}^{2+}$ ions indicated a positive effect on antibacterial activity [43].

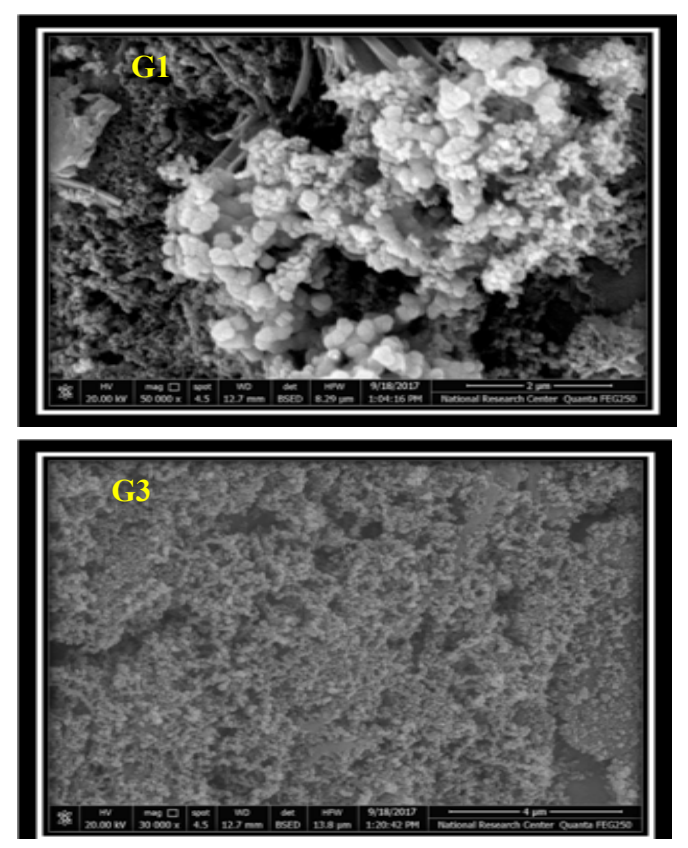

Fig . 4. SEM of prepared glasses after immersion in SBF.

Egypt.J.Chem. 61, No.1 (2018) 
TABLE 2. Antimicrobial activity of prepared glasses measured by the agar diffusion technique.

\begin{tabular}{|c|c|c|c|c|c|c|c|}
\hline \multirow{6}{*}{$\begin{array}{c}\text { Glass } \\
\text { Sample }\end{array}$} & \multicolumn{7}{|c|}{ Inhibition zone diameter (IZD) (mm) } \\
\hline & \multirow{2}{*}{\multicolumn{2}{|c|}{$\begin{array}{l}\text { Gram positive } \\
\text { bacteria }\end{array}$}} & \multirow{2}{*}{\multicolumn{2}{|c|}{$\begin{array}{c}\text { Gram negative } \\
\text { bacteria }\end{array}$}} & \multirow{3}{*}{$\begin{array}{c}\text { Yeast } \\
\text { C.albicans }\end{array}$} & \multirow{2}{*}{\multicolumn{2}{|c|}{ Fungi }} \\
\hline & & & & & & & \\
\hline & B. subtilis & S. aureus & E. coli & P.aeruginosa & & F.solani & A.niger \\
\hline & ATCC & ATCC & ATCC & ATCC & ATCC & NRC & NRC \\
\hline & 6633 & 29213 & 25922 & 27953 & 10321 & 18 & 53 \\
\hline Blank & 20 & 18 & N.A. & N.A. & 13 & 13 & N.A. \\
\hline G1 & $17 \pm 1.2$ & $16 \pm 0.3$ & N.A. & N.A. & N.A. & N.A. & N.A. \\
\hline G2 & $13 \pm 0.5$ & $15 \pm 0.2$ & N.A. & N.A. & $18 \pm 0.4$ & $15 \pm 1.6$ & N.A. \\
\hline G3 & N.A. & $14 \pm 1.1$ & N.A. & N.A. & $16 \pm 0.3$ & $25 \pm 1.5$ & N.A. \\
\hline
\end{tabular}

N.A.No activity. The average values are reported as Mean \pm SD calculated using MS Excel.

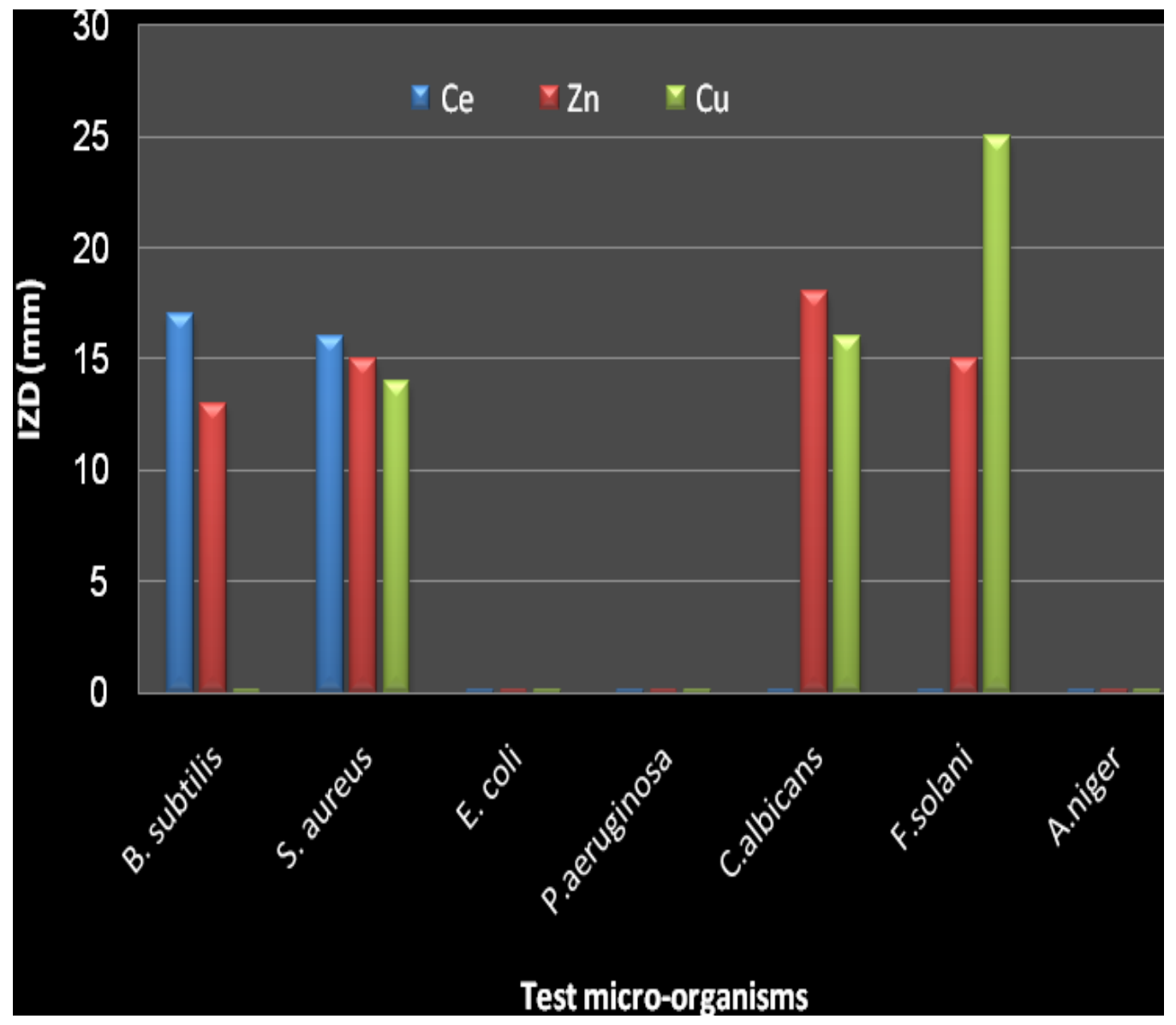

Fig .5. Antimicrobial activity of prepared glasses measured by the agar diffusion technique. 


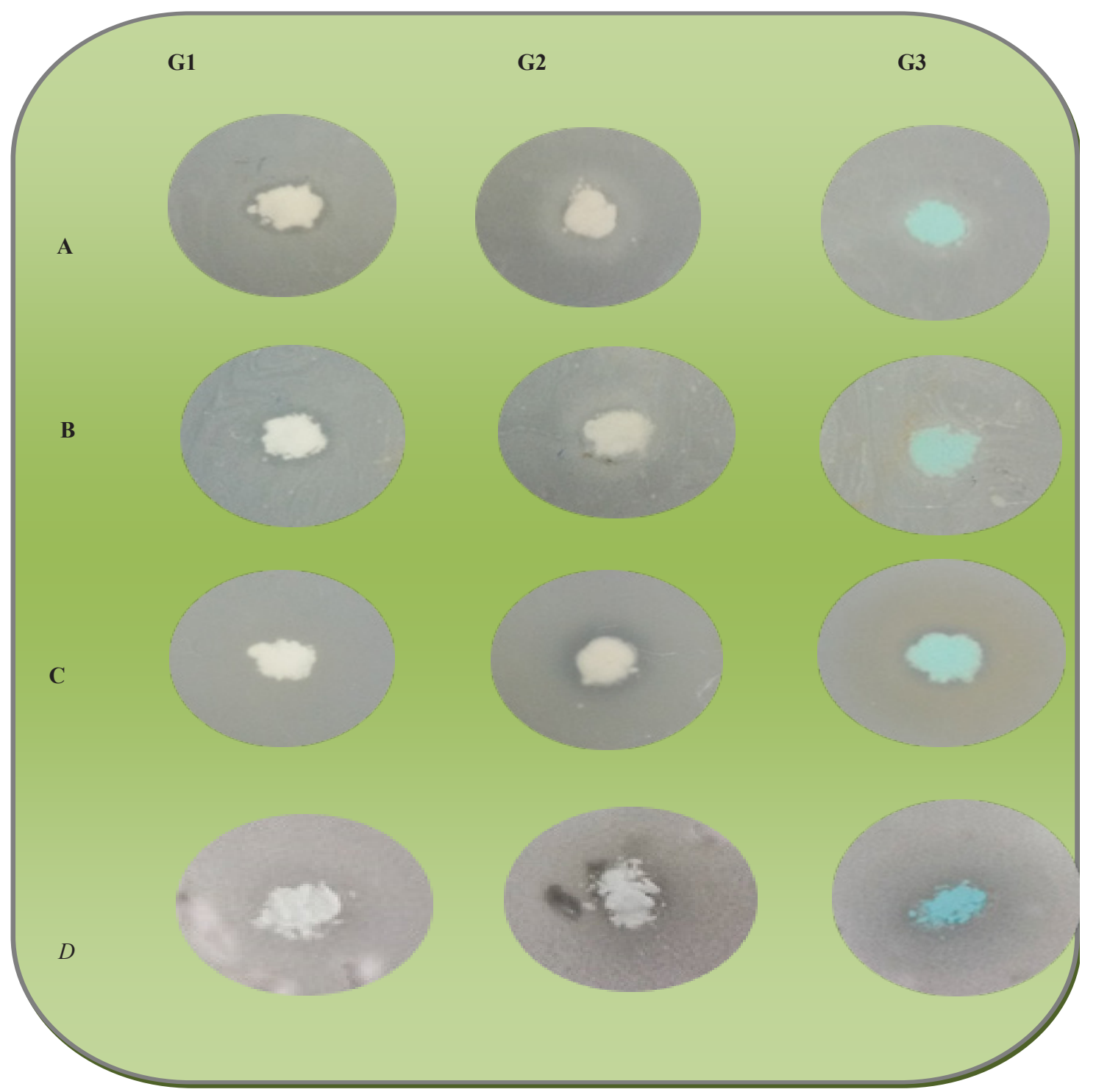

Fig .6. Photos of agar-diffusion assays of samples contained $(\mathrm{Ce}, \mathrm{Zn}$ and $\mathrm{Cu})$ with tested Micro-organisms. A, B. subtilis.B, S. aureus.C, C.albicans. D, F. solani.

\section{Conclusions}

Three different compositions in the system $\left(\mathrm{B}_{2} \mathrm{O}_{3} \cdot \mathrm{P}_{2} \mathrm{O}_{5} \cdot \mathrm{CaF}_{2} \cdot \mathrm{Na}_{2} \mathrm{O} \cdot \mathrm{XO}\right)$ where $\mathrm{X}$ is one of the antibacterial elements $(\mathrm{Ce}, \mathrm{Zn}, \mathrm{Cu})$ were prepared. FTIR absorption spectra and weight loss $\%$ of the prepared glasses before and after immersion in SBF for 2 weeks were investigated. Samples showed a bioactive response in simulated body fluid (SBF).A Ca-P layer was indicated on the samples surface by the distinctive peaks of calcium phosphate group between 481 and 623 $\mathrm{cm}^{-1}$. Also the antimicrobial application of the prepared glass was performed. All results assured the bioactivity of the prepared glasses. The dissolution of bioactive glass in SBF ensures the bioactivity especially in case of the $\mathrm{CeO}_{2}$ sample. SEM similarly confirmed the bioactivity of the glass system by the development of a uniform spherical shape of particles and size which perform better against the bacterial infections.

\section{$\underline{\text { References }}$}

1. Akram M. and Hussain R., Antibacterial properties of bioactive glasses trends, and novel approaches, clinical applications of biomaterials, Springer,pp 357-382 (2017).

Egypt.J.Chem. 61, No.1 (2018) 
2. Yadav M.R., Raja J.B., Avinash M. and Ch.R. Ravikumar R.V.S.S.N., Structural and optical properties of $\mathrm{Cu}$ (II) ions doped calcium borophosphate (CaBP) nanophosphor by solidstate synthesis. J. Mater. Sci. Mater Electron, 27, 1318 (2016).

3. Baia L., Muresan D., Baia M., Popp J. and Simon S., Structural properties of silver nanoclustersphosphate glass composites. Vib. Spectrosc., 43, 313 (2007).

4. Saranti A., Koutselas I. and Karakassides M.A., Bioactive glasses in the system $\mathrm{CaO}-\mathrm{B}_{2} \mathrm{O}_{3}$ $\mathrm{P}_{2} \mathrm{O}_{5}$ : Preparation, structural study and in vitro evaluation. J. Non-Cryst. Solids, 352, 390 (2006).

5. Lakhkar N.J., Lee I-H., Kim H-W., Salih V., Wall I.B. and Knowles J.C., Bone formation controlled by biologically relevant inorganic ions: Role and controlled delivery from phosphate-based glasses. Advanced Drug Delivery Reviews, 65, 405(2013).

6. Karabulut M., Popa A., Borodi G. and Stefan R., An FTIR and ESR study of iron doped calcium borophosphate glass-ceramics. Journal of Molecular Structure, 1101,170 (2015).

7. Lysenko O., Dubok O., Borysenko A. and Shinkaruk O., The biological properties of the silver and copper-doped ceramic, Biomaterial. J. Nanopart. Res., 17, 178 (2015).

8. Stoor P., S€oderling E. and Salonen J.I., Antibacterial effects of a bioactive glass paste on oral microorganisms. Acta Odontol. Scand., 56,161 (1998).

9. Irving Sax N. and Lewis Sr R.J., In: Dangerous Properties Of Industrial Materials, 7th Ed., vol. 2, Van Nostrand Reinhold, 743 (1989)

10. Hall S.L., Dimai H.P. and Farley J.R., Effects of zinc on human skeletal alkaline phosphatase activity. In Vitro, 64, 163 (1999).

11. $\mathrm{Wu}$ X.W., Itoh N., Taniguchi T., Nakanishi T., Tatsu Y. and Yumoto N., et al., Zinc-induced sodium dependent vitamin $\mathrm{C}$ transporter 2 expression: potent roles in osteoblast differentiation. Arch Biochem Biophys, 420, 114 (2003).

12. Tang Z-L., Wasserloos K., Croix C.M.St. and Pitt, B.R., Role of zinc in pulmonary endothelial cell response to oxidative stress. Lung Cellular and Molecular Physiology 28, 243 (2001).
13. Holloway W.R., Collier F.M., Herbst R.E., Hodge J.M. and Nicholson G.C., Osteoblast-mediated effects of zinc on isolated rat osteoclasts: Inhibition of bone resorption and enhancement of osteoclast number. Bone, 19,137 (1996).

14. Lusvardi G., Malavasi G., Menabue L. and Menziani M.C., Properties of zinc releasing surfaces for clinical applications. J. Phys. Chem., B 106, 9753(2002).

15. Gerard C., Bordeleau L.J., Barralet J. and Doillon C.J., The stimulation of angiogenesis and collagen deposition by copper. Biomaterials, 31, 824 (2010).

16. Abo-Naf Sh., Khalil El-Sayed, El-Sayed M., Zayed H. and Youness R., In vitro bioactivity evaluation, mechanical properties and microstructural characterization of $\mathrm{Na}_{2} \mathrm{O}-\mathrm{CaO}-\mathrm{B}_{2} \mathrm{O}_{3}-\mathrm{P}_{2} \mathrm{O}_{5}$ glasses. SpectrochimicaActa Part A: Molecular and Biomolecular Spectroscopy, 144, 88 (2015).

17. Sherief, M., Hanna, A., Elkheshen, A., Abd El Aty, A., Studies on the bioactive effects of incorporate some rare earth elements into basic glass materials. Rasayan J. Chem., 9, 531 (2016).

18. El-Batal F., El-Kheshen A., El-Bassyouni G. and Abd El Aty A., In vitro bioactivity behavior of some borate glasses and their glass-ceramic derivatives containing $\mathrm{Zn}^{2+}, \mathrm{Ag}^{+}$or $\mathrm{Cu}^{2+}$ by immersion in phosphate solution and their antimicrobial activity. Silicon, DOI: 10.1007/s12633017-9552-y,(2017).

19. Mourin o V., Cattalini J. and Boccaccini A., Metallic ions as therapeutic agents in tissue engineering scaffolds: an overview of their biological applications and strategies for new developments. J. R. Soc. Interface., 9, 401 (2011).

20. Jung S., Borate based bioactive glass scaffolds for hard and soft tissue engineering, Ph.D dissertation, Missouri University of Science and Technology (2010).

21. Deliormanli A., Synthesis and characterization of cerium- and gallium-containing borate bioactive glass scaffolds for bone tissue engineering. $J$ Mater Sci: Mater Med, 26, 67(2015).

22. Deliormanli A. and Yıldırım M., Sol-gel synthesis of 13-93 bioactive glass powders containing therapeutic agents. Journal of the Australian Ceramic Society, 52(2), 9 (2016).

23. Das S., Singh S., Dowding J., Oommen S., Kumar 
A., Sayle T., Saraf S., Patra C., Vlahakis N., Vlahakis D., Self W. and Seal S., The induction of angiogenesis by cerium oxide nanoparticles through the modulation of oxygen in intracellular environments. Biomater., 33,7746(2012).

24. Salinas AJ.,Shruti S., Malavasi G., Menabue L., Vallet-Regi M., Substitution of cerium, gallium and zinc in ordered mesoporous bioactive glasses. Acta Biomater., 7, 3452 (2011).

25. Riaz M., Zia R., Saleemi F., Bashir F., Hossain T. and Kayani Z., In vitro evaluation of bioactivity of $\mathrm{SiO}_{2}-\mathrm{CaO}-\mathrm{P}_{2} \mathrm{O}_{5}-\mathrm{Na}_{2} \mathrm{O}-\mathrm{CaF}_{2}-\mathrm{ZnO}$ glass-ceramics. Materials Science-Poland, 32(3), 364 (2014).

26. Alijanian Z., Talebian N. and Doudi M., Bactericidal activity of copper oxide nanocomposite/bioglass for in vitro clindamycin release in implant infections due to staphylococcus aureus. J. Med. Biochem., 4, e38596 (2016).

27. Ouis M., Abdelghany A. and ElBatal H., Corrosion mechanism and bioactivity of borate glasses analogue to Hench's bioglass. Processing And Application Of Ceramics, 6,141 (2012).

28. Misra S., et al., Poly (3-hydroxybutyrate) multifunctional composite scaffolds for tissue engineering applications. Biomaterials, 31, 2806 (2010).

29. Gorriti M., et al., In vitro study of the antibacterial activity of bioactive glass-ceramic scaffolds. $A d v$. Eng. Mater., 11,67 (2009).

30. Sepulveda P., Jones J. and Hench L., In vitro dissolution of melt-derived 45S5 and sol-gel derived 58S bioactive glasses. J. Biomed. Mater Res., 61, 301 (2002).

31. Balamurugan A., et al., An in vitro biological and anti-bacterial study on a sol-gel derived silverincorporated bioglass system. Dent. Mater., 24,1343 (2008).

32. Abdelghany A., Ouis M., Azooz M., ElBatal H. and El-Bassyouni, G., Role of $\mathrm{SrO}$ on the bioactivity behavior of some ternary borate glasses and their glass ceramic derivatives. Spectrochimicaacta Part A: Molecular and Biomolecular Spectroscopy, 152,126 (2016).

33. Day D., Reactions of bioactive borate glasses with physiological liquids. Glass Res., 12, 21 (2002).

34. Huang W., Rahman M. and Day D., Conversion of silicate (45S5), borate, and borosilicate glasses to hydroxyapatite in dilute phosphate solution.
Ceram. Eng. Sci. Proc., 27,131 (2006).

35. Han X. and Day D., Reaction of sodium calcium borate glasses to form hydroxyapatite. J. Mater. Sci. Mater. Med., 18,1837 (2007).

36. Gu Y., Xiao W., Huang W., Rahaman M. and Wang D., Kinetics and mechanisms of converting borate bioactive glasses to hydroxyapatite in aqueous phosphate solution. J. Mater. Sci., 46, 47 (2011).

37. Saqaei M., et al. Effects of adding for steritebioceramic on in vitro activity and antibacterial properties of bioactive glass-for steritenano composite powders. Adv. Powder Technol., 27, 1922 (2016).

38. Prabhu M., Ruby Priscilla S., Kavitha K., Manivasakan P., Rajendran V. and Kulandaivelu P., In vitro bioactivity and antimicrobial tuning of bioactive glass nanoparticles added with neem (Azadirachtaindica) leaf powder. Biomed Res Int., 2014,1 (2014).

39. Gu Y., Huang W., Rahaman M. and Day D., Bone regeneration in rat calvarial defects implanted with fibrous scaffolds composed of a mixture of silicate and borate bioactive glasses. ActaBiomater., 9, 9126 (2013).

40. Leonelli C., Lusvardi G., Malavasi G., Menabue L. and Menabue M., Synthesis and characterization of cerium-doped glasses and in vitro evaluation of bioactivity. J. Non-Cryst. Solids, 316 (2-3), 198 (2003).

41. Fu Q., Rahaman M., Fu H. and Liu X., Silicate, borosilicate, and borate bioactive glass scaffolds with controllable degradation rate for bone tissue engineering applications. I. Preparation and in vitro degradation. J. Biomed. Mater. Res., Part A., 95,164 (2010).

42. Shruti S., Salinas A., Malavisa G., Lusvardi G., Menabue L., Ferrara C., Mustarelli P. and ValletRegi M., Structural and in vitro study of cerium, gallium and zinc containing sol-gel bioactive glasses. J. Mater. Chem., 22,13698 (2012).

43. Neel E., Ahmed I., Pratten J., Pratten S. and Pratten J., Characterization of antibacterial copper releasing degradable phosphate glass fibers. Biomaterials, 26, 2247(2005).

(Received 17/12/2017; accepted 14/1/2018)

Egypt.J.Chem. 61, No.1 (2018) 


\section{تجهيزو توصيف بعض زجاج البوروفوسفات المحتوى على أكاسيد مضاده للبكتريا والفطريات وتظبيقها فى الاحتياجات الحيويه

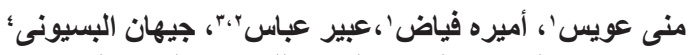

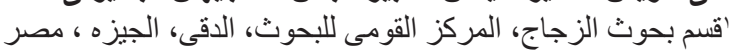



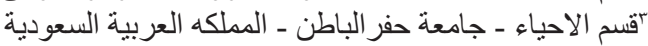

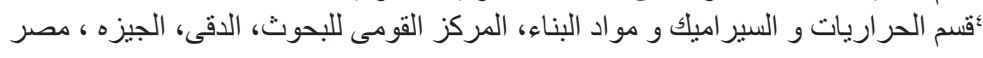

تم تحضير سلسله من التركيات المختلفه من زجاج البوروفوسفات المحتوى على بعض الاكاسيد المقاومه



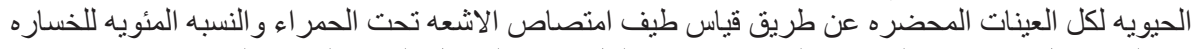

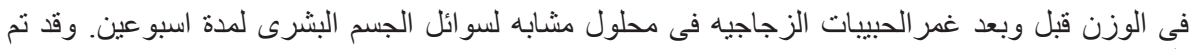

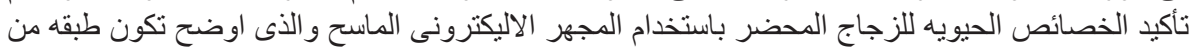

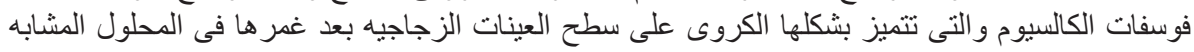



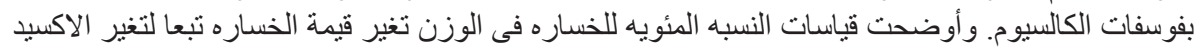

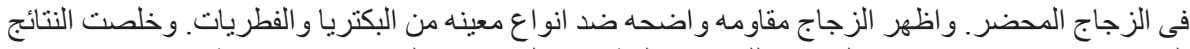


النشاط الحيوي للزجاج المحضر وربما يجد مجالا فى التطبيقات الحيويه الطبيه. 